\title{
Colombian metallurgical coke as catalysts support of the direct coal liquefaction
}

\author{
Diego Rico $^{\mathrm{a}}$, Yazmin Agámez $^{\mathrm{a}}$, Eduard Romero ${ }^{\mathrm{a}}$, Miguel Ángel Centeno ${ }^{\mathrm{b}}$, \\ José Antonio Odriozola ${ }^{\mathrm{b}}$, José de Jesús Díaz ${ }^{\mathrm{a}, *}$ \\ ${ }^{a}$ Departamento de Química, Universidad Nacional de Colombia, Av. Carrera 30 No. 45-03, \\ Bogotá, D. C., Colombia \\ ${ }^{b}$ Instituto de Ciencia de Materiales de Sevilla, Universidad de Sevilla-CSIC, Av. Américo \\ Vespucio 49, Sevilla, España
}

\begin{abstract}
A Colombian metallurgical coke was modified in its surface chemistry and was used as support of iron sulfide catalysts for direct coal liquefaction. The modification was made by treatments with diluted oxygen and $\mathrm{HNO}_{3}$ at different conditions. Changes in surface chemistry were studied by determining the point of zero charge (PZC), the isoelectric point (IEP), thermogravimetric analysis (TGA), temperature programmed decomposition - mass spectrometry (TPDMS), Diffuse-reflectance infrared Fourier transform spectroscopy (DRIFTS) and nitrogen adsorption at $77 \mathrm{~K}$. The results show that the materials obtained have a wide range of functional groups incorporated in a different proportion and quantity. The textural parameters indicate that treatment with diluted oxygen increases the surface area and incorporates micropores while the samples treated with $\mathrm{HNO}_{3}$ maintain the textural properties of the original material. The catalysts were also characterized by Raman spectroscopy. It was found that impregnation with the iron sulfide precursor does not significantly affect the Raman characteristics of the support. Additionally, XRD analysis shows smaller pyrite crystallites in the coke enriched with oxygenated groups of phenol and lactone indicating better dispersion of the active phase. The amount of oxygen chemisorbed per gram of catalyst shows that both, oxygen and ni-
\end{abstract}

\footnotetext{
${ }^{*}$ Corresponding author

Email address: jddiazv@unal.edu.co (José de Jesús Díaz)
}

Preprint submitted to FUEL

June 30, 2019 
tric acid treatments, improve the relative dispersion of the active phase. It was found that the presence of the catalysts increases the conversion and yields towards oils and gases with respect to those of the tests without catalysts. Cokes modified by dilute oxygen gaseous treatment contain surface phenol and lactone groups and present the highest yield to oils.

Keywords: metallurgical coke, surface chemistry, direct coal liquefaction, dispersion.

\section{Introduction}

Direct coal liquefaction (DCL) could become a viable option to produce liquid fuels [1; however, the high operational costs and the variable price of a barrel of oil make difficult its economic viability. The combination of highly 5 reactive coals and efficient catalysts could lower the severity of reaction conditions and lower production costs [2, 3]. A catalyst useful in DCL should promote hydrogenation, cracking, hydrocracking and the removal of heteroatoms reactions. The catalysts most used in the DCL are iron sulfides due to its low cost although its activity is not the highest [4. From the studies carried out with bulk catalysts, catalysts impregnated directly on the coal to be liquefied and supported catalysts [5, 6, 7, it is inferred that, the latter are preferred because they are suitable for hydrogenating the coal, reduce operating costs, increase the dispersion of the active phase and some supports allow the recovery of the metal; however, they are rapidly deactivated by deposition of carbonaceous material on the active phase [3].

The carbonaceous materials have been widely used as adsorbents, catalysts and more important as support for catalysts, due to the ease of changing of its physicochemical properties [8]. This flexibility is a consequence of its porous structure, because it determines the diffusion of reactants and products to and from the surface, its surface area, that determines the loading and dispersion of the active phase, its chemical structure, which provides interactions with other different nature molecules (reagents, products, precursors and active phases) 
and an acid-base character able to improve its performance [9, 10].

The surface chemistry of the carbonaceous materials is governed mainly by the presence of structural defects and heteroatoms, such as oxygen, nitrogen and sulfur which can form stable surface complexes, which directly affect interaction with other molecules, such as catalytic precursors or reagents, improving the dispersion, selectivity and conversion. In general, the concentration of oxygenated groups on the surface can be increased by gaseous or aqueous oxidation.

so Oxidation in aqueous phase generally increases the concentration of carboxylic acids and does not dramatically affect the textural properties of the material, improves the hydrophobicity and removes part of the mineral matter of the carbonaceous material. Among the oxidants reported, nitric and sulfuric acid are the ones most extensively studied [11, 12, 13]. On the other hand, oxidation with gaseous reactants favors the formation of carbonyl and hydroxyl groups and affects the textural properties of the material, increasing the surface area by decreasing the pore diameter [11, 14]. Another alternative is to selectively remove the pristine surface groups of the carbonaceous material with heating in inert gas or dilute oxygen [15]. The mechanism of reaction with oxygen, nitric acid and other oxidizing agents for the modification of different carbonaceous materials such as: carbon blacks, activated carbons and chars have been widely studied and it is generally accepted that the oxygen of the oxidizing agent chemisorbs dissociatively on the free active sites to form surface oxygen complexes, which decompose generating $\mathrm{CO}_{2}$ and/or $\mathrm{CO}$ and removing carbon atoms from the surface of the material, resulting in new sites that are exposed for subsequent chemisorption [16, 17].

Most of the catalysts used in the direct use liquefaction use metallic sulfurs, such as pyrite, which is very active in the hydrogenation process since favor the transference of gaseous hydrogen to the carbonaceous matrix. Additionally, in the DCL, iron-based conventional catalyst are used, which are supported on alumina, zeolites, or activated carbon among others; subsequently, a second metal is incorporated, such as nickel, cobalt, tungsten and molybdenum as catalyst promoters. In spite of all the existent techniques for the production of lique- 
faction catalysts, there is a great interest in the development of new catalysts highly active and selective, of low cost and environmental friendly. Currently, iron sludge or iron ore catalysts are used in suspension. There are researches related to the production of highly dispersed catalysts but none of them uses metallurgical coke as a support to benefit from the chemical and physical inalterability properties of this material [18, 19, 20, 21, 22, 23, 24.

In this regard, Díaz et al 18] have proposed a catalyst using metallurgical coke as support and which is able to withstand the conditions of the DCL and can support various metal sulfides as active phase [25], having as advantages over traditional supports the fact that they facilitate the recovery of the active phase, decrease the deposition of carbon, their textural properties and surface 65 chemistry are easily adjustable and show high affinity with the DCL products. However, the manufacturing process of metallurgical coke almost completely eliminates the surface chemistry of the material, making it difficult to interact with the catalytic precursors, reducing the efficiency of the impregnation and limiting the dispersion of the active phase [26]. Notwithstanding the above, metallurgical coke has a high potential to be used as catalyst support for this type of reactions that are often carried out at high temperatures and pressures so thus demand a much stronger thermal strength of the carbon framework.

In the last years it has seen a growth in research aimed at understanding of all physical and chemical aspects of carbonaceous materials, which have led to its 75 positioning as catalysts or supports; however, for the metallurgical coke is still a need to do studies linking their surface chemical characteristics and not only the surface area and porosity with their behavior as catalyst support. Hence, the objective of this paper was to evaluate the possibility of modifying the surface chemistry of a Colombian metallurgical coke by generating surface oxygenated 80 groups using both gaseous and liquid oxidizing agents such as dilute $\mathrm{O}_{2}$ and dilute $\mathrm{HNO}_{3}$ and, from this modification, explore the effect on the dispersion of the active phase in the production of liquid fuels from a Colombian coal. 


\section{Experimental}

\subsection{Materials and functionalization}

Metallurgical coke was selected as the starting material obtained from a blend of coking and caking Colombian coals which were heated to $1123 \mathrm{~K}$ in a nitrogen atmosphere for 1.5 hours, the material was ground and sieved to a particle size between 1.00 and $2.36 \mathrm{~mm}$. The obtained solid was denoted as COKE. Table 1 shows the results of the proximate and ultimate analysis for the coal and coke samples.

Table 1: Proximate and ultimate analysis

\begin{tabular}{ccccccccccc}
\hline & \multicolumn{4}{c}{ Proximate analysis, wt $\%$} & \multicolumn{4}{c}{ Ultimate analysis, ${ }^{c}$ wt $\%$} \\
& $\mathrm{VM}^{a}$ & $\mathrm{FC}^{a}$ & $\mathrm{ash}^{b}$ & $\mathrm{MM}^{b}$ & $\mathrm{C}$ & $\mathrm{H}$ & $\mathrm{N}$ & $\mathrm{S}$ & $\mathrm{O}$ \\
\hline Coal & 38.8 & 61.2 & 2.6 & 3.2 & 85.5 & 5.4 & 1.5 & 0.7 & 6.9 \\
\multicolumn{1}{l}{ Coke } & - & 99.9 & 8.8 & 9.9 & 90.4 & 0.2 & 1.7 & 0.8 & 6.9 \\
\hline \multicolumn{1}{l}{ dry, mineral matter-free basis. ${ }^{b}$ dry basis. ${ }^{c}$ dry, ash-free basis. }
\end{tabular}

To select the functionalization conditions, the COKE oxidation profile was performed on a TGA/DSC 1 STARe System (Mettler Toledo). Approximately $10 \mathrm{mg}$ were taken in a ceramic crucible of $150 \mu \mathrm{L}$ capacity in a flow of 30 $\mathrm{mL} / \mathrm{min}$ of air and a heating rate of $10 \mathrm{~K} / \mathrm{min}$ from $298 \mathrm{~K}$ to $1400 \mathrm{~K}$. For the functionalization of the surface at the macro level with dilute oxygen, $5 \mathrm{~g}$ of metallurgical coke were placed in a vertical quartz reactor inside a furnace that allows gas flow through the sample, the oven was heated at a rate of 10 $\mathrm{K} / \mathrm{min}$ from room temperature to selected temperature in the COKE oxidation profile. After was allowed to flow oxygen diluted to $9 \%$ in nitrogen at a flow of $50 \mathrm{~mL} / \mathrm{min}$ for different oxidation times $(18,21,24,30$ and $36 \mathrm{~h})$. The samples obtained by this method were called $\mathrm{CO}$ followed by a number indicating the time in hours of oxidation.

Functionalization of the surface of metallurgical coke with $\mathrm{HNO}_{3}$ was performed at different concentrations of nitric acid (4, 6, 9 and $12 \mathrm{M})$ in a batch reactor system with reflux. $12 \mathrm{~g}$ of coke and $120 \mathrm{~mL} \mathrm{HNO}$ was refluxed for 6 
h. The oxidized material was separated from the acid residue by filtration and was washed with deionized water in a semi-continuous system with reflux until the wash water is less than $5 \mathrm{ppm}$ nitrate ion. The materials were drying at 373 $\mathrm{K}$ in vacuum to constant weight; these materials were called as CXM where $\mathrm{X}$ is the concentration of nitric acid. The modification with nitric acid is carried out following the methodology described by Khelifi et al 27 .

\subsection{Synthesis of catalysts}

For the synthesis of the catalytic precursor, thiourea (Merck $\mathrm{H}_{2} \mathrm{NCSNH}_{2}$, 99.9\%), anhydrous iron II chloride $\left(\mathrm{FeCl}_{2}\right.$ Carlo Erba, 99.5\%) and anhydrous ethanol (Merck, 99.9\%) were employed. As catalytic supports, the raw metallurgical coke (COKE) and the modified materials with the best functionalization results were used.

The catalytic precursor, iron 2-chlorotetrakis-thiourea II (from now called Fe-tu) was synthesized according to the methodology described by Rosenheim et al. 28. The impregnation was carried out by drying the support and degassing at $333 \mathrm{~K}$ under vacuum and ultrasonic agitation for 45 minutes. An aqueous precursor solution flow $(1 \mathrm{~mL} / \mathrm{min})$ was added with a peristaltic pump in vacuum and ultrasonic agitation. The impregnated support was kept 12 hours with mechanical stirring at room temperature. The excess water was eliminated at $393 \mathrm{~K}$ until constant weight. Subsequently, the catalytic precursor was activated in a sealed glass reactor at $523 \mathrm{~K}$ for 24 hours, then washed and dried at $373 \mathrm{~K}$ [18, 25] [. The materials obtained were named COKE-Fe, CO36-Fe and C12M-Fe.

\subsection{Characterization techniques}

The study of oxygenated groups is realized from techniques such as mass titrations to determine the point of zero charge (PZC), isoelectric point (IEP), temperature programmed decomposition - mass spectrometry (TPD-MS), Diffusereflectance infrared Fourier transform spectroscopy (DRIFTS), thermogravimetric analysis (TGA) and physiadsorption of nitrogen at $77 \mathrm{~K}$ [11, 15, 27]. The 
fluorescence (XRF), dynamic oxygen chemisorption and SEM.

The PZC was determined following the methodology described by Noh [29]. The materials were ground to particles less than 100 mesh and a suspension with different percentages by weight/weight $(\mathrm{w} / \mathrm{w})$ in deionized and degassed water are prepared. Finally, after that stirred for 48 h, it was determined the pH of the suspension from the graph of final $\mathrm{pH}$ versus solid content $(\mathrm{w} / \mathrm{w})$ being the PZC the $\mathrm{pH}$ to which the graph converges asymptotically. The Zeta potential of the suspension of the modified materials was determined on a Malvern instrument Zetamaster with red laser $(633 \mathrm{~nm})$ of Ne-He. To which $20 \mathrm{mg}$ of each material were suspended in $500 \mathrm{~mL}$ of $95 \%$ ethanol; the ionic strength was adjusted with $\mathrm{NaCl}$ and $\mathrm{pH}$ with $\mathrm{HCl}$ and $\mathrm{NaOH}$ solutions homogenized in an ultrasonic bath prior to measurement with a pH meter CRISON52 23. The IEP was defined as the $\mathrm{pH}$ at which Zeta potential is zero.

The thermal stability of the functionalized materials was determined on a TGA/DSC 1 STARe System (Mettler Toledo) by using $0.010 \mathrm{~g}$ of solid, a flow of $30 \mathrm{~mL} / \mathrm{min}$ of nitrogen and a heating rate of $10 \mathrm{~K} / \mathrm{min}$ from $298 \mathrm{~K}$ to 1373 K. The identity of the functional groups was determined by the TPD profiles on a Quanta Chrome Autosorb iQ2 instruments with a quartz U reactor. For each test, $0.1 \mathrm{~g}$ of material was deposited and subjected to a heating rate of $5 \mathrm{~K} / \mathrm{min}$ up to $1350 \mathrm{~K}$ in a He flow $30 \mathrm{~mL} / \mathrm{min}$ and the desorbed gases were continuously analyzed in a mass spectrometer Pfeiffer vacuum(R)where it was determined the evolution of $\mathrm{CO}$ and $\mathrm{CO}_{2}$ following the $\mathrm{m} / \mathrm{z}=28$ and 44 signals, respectively. The calibration factors for the mass spectrometer were determined using He as internal standard and following the response $\mathrm{CO}$ and $\mathrm{CO}_{2}$ signals of a $1 \% \mathrm{v} / \mathrm{v}$ flow of the corresponding gas in He, as recommended by Quanta Chrome. To determine the identity of each functional group, a deconvolution of the graphs of $\mathrm{CO}$ and $\mathrm{CO}_{2}$ desorption signals was performed. From the temperature of maximum evolution of these signals and according to the information reported by Figueiredo et. al. [17, a functional group is assigned to each desorption 165 event observed. 
Textural properties were measured by adsorption isotherms obtained on a Micromeritics ASAP 2010. For this purpose, the materials were degassed for 24 $\mathrm{h}$ at $523 \mathrm{~K}$; surface area (SBET) was calculated using the Brunauer-EmmettTeller (BET) model, the total pore volume was determined from the volume of

${ }_{170} \mathrm{~N}_{2}$ adsorbed at the relative pressure $\mathrm{P} / \mathrm{P}_{0}$ of $0.99\left(\mathrm{~V}_{T}=\mathrm{V}_{A D S} \times 0.001547\right)$ and the pore diameter was calculated assuming a cylindrical model $(\mathrm{Dp}=$ $\left.4 \mathrm{VT} / \mathrm{S}_{B E T}\right)$. RAMAN spectra were obtained using a Raman dispersive microscope Horiba Jobin Yvon LabRam (HR800) equipped with a green laser (532 $\mathrm{nm}, 20 \mathrm{~mW}$ ), and a CCD detector.

The crystalline phases of the materials were determined by X-ray diffraction in a Panalytical PRO X'pert equipment equipped with a $\mathrm{Cu}-\mathrm{K} \alpha$ radiation source $(\lambda=1.54060 \AA)$ using the X'pert HighScore database. The crystallite size for pyrite was determined with the Scherrer equation with the X'pert HighScore version 3.0c (3.0.3) program, using the average width of the plane (200) located at $33^{\circ}(2 \theta)$ and a form factor of 1 . The size of the graphite microcrystals of the coke was determined with the Scherrer equation using the mean width of the plane (002) located at $26.6^{\circ}(2 \theta)$ and 0.9 as the form factor. The chemical composition of the materials was determined in an AXIOS PW4400 Panalytical wavelength dispersion fluorescence spectrophotometer, with rhodium anode as radiation source.

The dynamic oxygen chemisorption was performed in a U-shaped quartz tube, the temperature was increased to $333 \mathrm{~K}$ and maintained while the $5 \%$ $\mathrm{v} / \mathrm{v}$ diluted oxygen injections in argon were carried out. The oxygen signal was monitored by a Pfeiffer Vacuum premium mass spectrometer plus TMU 071, until the difference of two consecutive signals was less than $3 \%$. The SEM images were obtained in a scanning electron microscope Hitachi S-4800 SEMFEG.

\subsection{Direct coal liquefaction}

For the liquefaction catalytic tests, a high volatile A bituminous Colombian coal (RC) according with ASTM D-388 was selected (table 1), ground, sieved 
to a size less than $125 \mu \mathrm{m}$ and dried at $393 \mathrm{~K}$ for $2 \mathrm{~h}$. Tetralin was used as a solvent for liquefaction $\left(\mathrm{C}_{10} \mathrm{H}_{12}\right.$ Merck, 98\%). Nitrogen ( $\mathrm{N}_{2}$ Cryogas S.A., grade 5.0) was used to purge the reactor and hydrogen $\left(\mathrm{H}_{2}\right.$ AGA S.A. grade 4.5) was used as the reactant gas.

For each catalytic test, $15 \mathrm{~g}$ of $\mathrm{RC}, 25 \mathrm{~g}$ of tetralin $\left(\mathrm{C}_{10} \mathrm{H}_{12}\right.$ Merck, $98 \%$ purity), and $1.5 \mathrm{~g}$ of catalyst were introduced in a Parr-type reactor of $250 \mathrm{~mL}$ capacity; the reactor was hermetically sealed and three discontinuous purges were made and a continuous one for 5 minutes with $\mathrm{N}_{2}$, the reactor was pressurized with $7.5 \mathrm{MPa}$ of $\mathrm{H}_{2}$, the magnetic stirring was adjusted at $240 \mathrm{rpm}$ and the heating was allowed up to $723 \mathrm{~K}$ at a speed of $10 \mathrm{~K} /$ min maintaining these conditions for one hour, these process conditions were established previous literature studies [5, 30, 31, 32, as well as conditions studied by our group [18, 25, 33. As a blank of the reaction, three tests were carried out under the same conditions but in the absence of any catalyst. Additionally, to determine the catalytic effect (if any) of the support, liquefaction was carried out using the raw COKE material in the same proportion as the catalyst. The stability of the coke used as a support in the catalysts was tested under the same reaction conditions, but without coal.

For the quantification of the reaction the procedure described in the flowchart of figure 1 was followed, adapted and established in accordance with the literature [30, 31, 34, liquid and solid products were exhaustively removed from the reactor and weighed $\left(W_{1}\right)$, and then subjected to successive extractions with different solvents in a soxhlet system for 24 hours. The first extraction was done with n-hexane, and the insoluble fraction was dried and weighed $\left(W_{2}\right)$. To determine the quantity of oils the following expression was used $\left(W_{\text {Oils }}=W_{1}-W_{2}-W_{T}\right)$. This insoluble fraction was extracted with acetone, the insoluble fraction was dried and weighed $\left(W_{3}\right)$, thus determining the amount of asphaltenes $\left(W_{A s}=W_{2}-W_{3}\right)$ and finally the previous insoluble fraction was extracted with THF and the insoluble residue was dried and weighed ${ }_{225}\left(W_{4}\right)$ which determined the amount of preasphaltenes $\left(W_{P A}=W_{3}-W_{4}\right)$. Given the difference in particle size (catalyst $1.33 \mathrm{~mm}$ and coal less than $125 \mu \mathrm{m}$ ), it 
was possible to separate the catalyst from the carbonaceous residue. In this way, the solid residue containing catalyst and carbonaceous residue was sieved with mesh \#18, where the retained fraction is the catalyst $\left(W_{C}\right)$ and the carbonaceous residue that is of smaller particle size was weighed $\left(W_{R}\right)$.

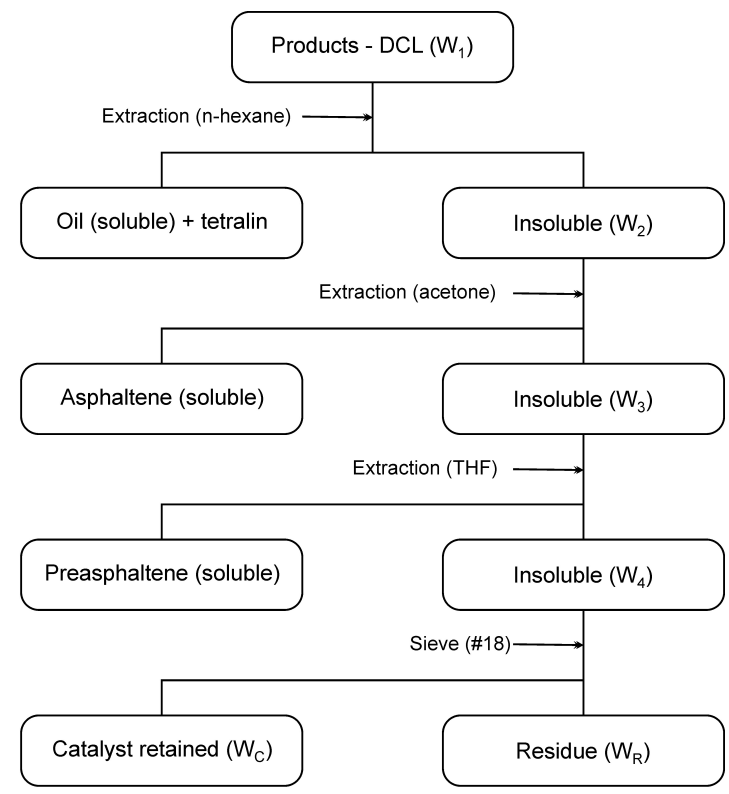

Figure 1: Flow diagram for the extraction process

Finally, the following equations were used to determine the conversion of coal and the yield to the different fractions:

$$
\begin{gathered}
X_{C}(\%)=\frac{W_{S, d b}-W_{R}}{W_{S, d a f}} \times 100 \\
Y(\%)=\frac{W_{\text {fraction }}}{W_{S, \text { daf }}} \times 100
\end{gathered}
$$

where $W_{S, d b}, W_{R}, W_{\text {fraction }}$ and $W_{S, d a f}$ correspond to the weight of the sample in dry basis, residue, fraction and sample in dry ash free basis, respectively. The gas yield was determined indirectly by the following expression:

$$
Y_{G}(\%)=\frac{W_{B, D C L}-W_{1}}{W_{S, d a f}} \times 100
$$


where $W_{B, D C L}$ corresponds to the weight of the reaction mixture (coal, combustion begins, presenting the maximum speed of mass loss at $935 \mathrm{~K}$ and ending at $1030 \mathrm{~K}$. According to these results, the temperature of $698 \mathrm{~K}$ was selected to functionalize the material since the period of oxygen chemisorption ends and stabilization is observed in the mass change.

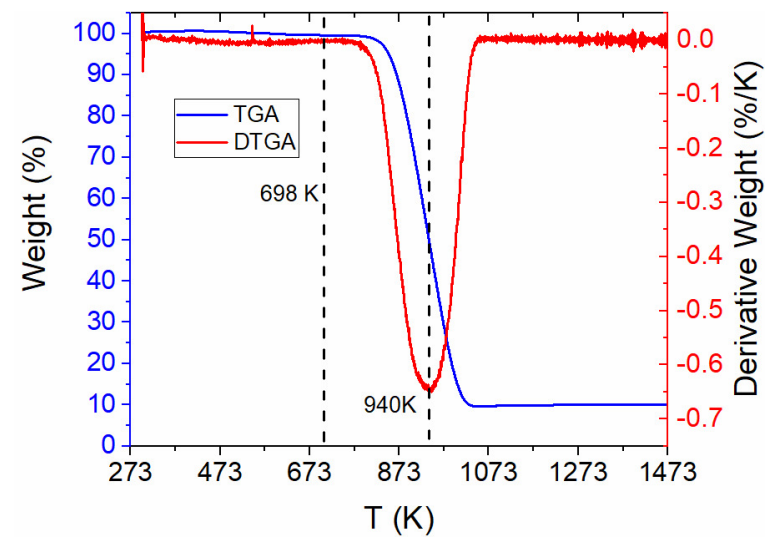

Figure 2: Coke combustion profile

Figure 3 shows the $\mathrm{N}_{2}$ adsorption isotherms for the COKE and the modified materials. These isotherms are type II according to the IUPAC classification [35]. The amount of nitrogen adsorbed initially increases slightly at low $\mathrm{P} / \mathrm{P}_{0}$, followed by a linear increase until $\mathrm{P} / \mathrm{P}_{0}$ close to 0.9 which it becomes more noticeable for higher relative pressures. This behavior is characteristic of materials with a heterogeneous mesoporosity [14].

Table 2 shows the comparison of the textural characteristics for the modified 

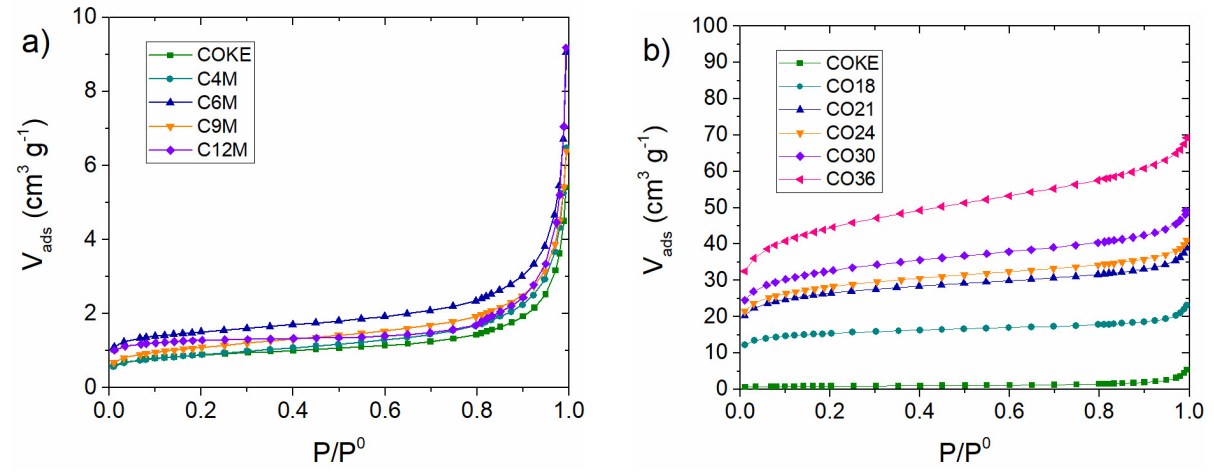

Figure 3: Nitrogen adsorption isotherms. a) Coke and modified materials with nitric acid. b) Modified materials with oxygen.

materials and the COKE, it is evident that treatment with gaseous diluted oxygen affects the physical and chemical properties of the material increasing the $S_{B E T}$ and $V_{\text {total }}$, due to the formation of new pores and open pores before treatment were not available [36], the $\mathrm{Dp}$ decreases but remains in the mesoporous range indicating that, although the surface area increases more than 20 times, the mesoporous character of the materials, which is desirable for catalytic purposes, such as the maximization of the active phase dispersion and the avoidance of diffusional reactions problems, is not lost. Treatment with $\mathrm{HNO}_{3}$ slightly affects the textural properties of coke, however at high concentrations of $\mathrm{HNO}_{3}$ (12 M) a slight increase in the surface area and pore diameter, possibly under these conditions is observed the pore walls wear [37. Unlike other carbonaceous materials [11, 13, 37. coke shows greater resistance in acidic environments and allows modification of their surface chemistry without drastically affecting their textural properties.

The zero charge point allows to establish the total net charge distribution (external and internal) of the particles [38. The Figure 4 shows that the PZC of the starting COKE sample is 6.6 indicating that it has surface oxygen groups weakly acidic or in low proportion. Both $\mathrm{CO}$ and CXM series have a systematic decrease of PZC with increased oxidation time and acid concentration, indicating that both oxidation treatments result in the incorporation of more 
Table 2: Effect of oxidative treatments in the textural characteristics

\begin{tabular}{cccc} 
Sample & $S_{B E T}\left(\mathrm{~m}^{2} / \mathrm{g}\right)$ & $V_{\text {total }}\left(\mathrm{cm}^{3} / \mathrm{g}\right)$ & $D_{p}(\mathrm{~nm})$ \\
\hline $\mathrm{CO} 36$ & 164 & 0.107 & 2.6 \\
$\mathrm{CO} 30$ & 122 & 0.076 & 2.5 \\
$\mathrm{CO} 24$ & 106 & 0.064 & 2.4 \\
$\mathrm{CO} 21$ & 99 & 0.060 & 2.4 \\
$\mathrm{CO} 18$ & 59 & 0.036 & 2.4 \\
$\mathrm{C} 12 \mathrm{M}$ & 5 & 0.014 & 12.2 \\
$\mathrm{C} 9 \mathrm{M}$ & 4 & 0.010 & 10.1 \\
$\mathrm{C} 6 \mathrm{M}$ & 4 & 0.009 & 10.1 \\
$\mathrm{C} 4 \mathrm{M}$ & 3 & 0.008 & 10.1 \\
$\mathrm{COKE}$ & 3 & 0.008 & 10.3 \\
\hline
\end{tabular}

oxygenated groups with acid character.
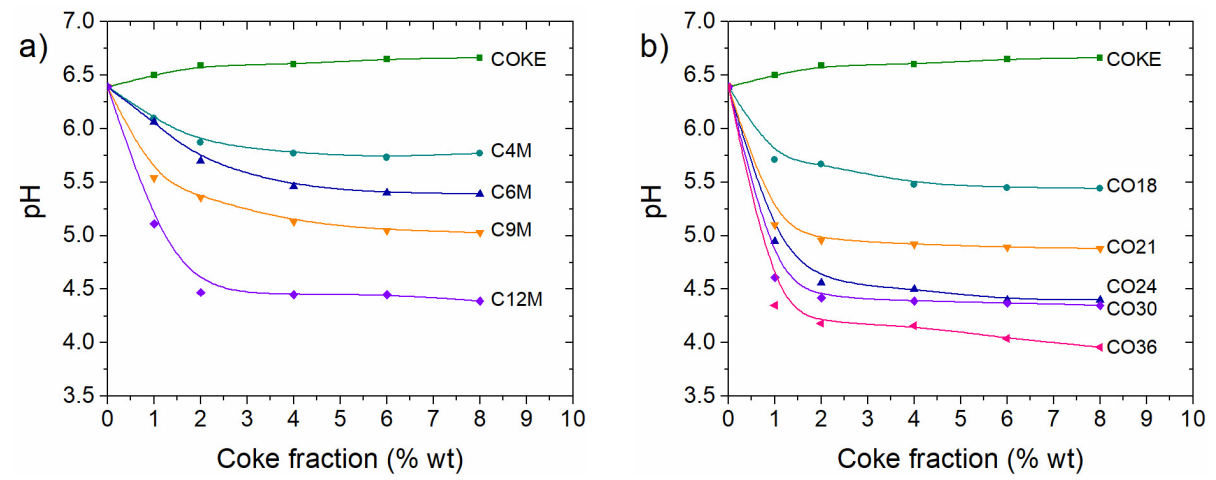

Figure 4: Determination of the point of zero charge. a) Coke and modified materials with nitric acid. b) Modified materials with oxygen.

In assessing the IEP, which is associated with the charge provided by the external surface of the carbonaceous material, it was found that oxidized materials also have lower values (table 3). On the other hand, the difference between PZC and IEP indicates the distribution of the charge through the particle [38. The results of table 3 show that oxygenated groups on the starting material are found primarily on the surface particles and they are formed during the 
process of shutting down the coke with water, which acts as a weak oxidant in a short contact time, although in the coke production process, the material has been subjected to high temperature in reducing atmosphere eliminating surface groups of oxygen. The treatment with diluted oxygen promotes the formation of oxygenated groups homogeneously distributed through the mass of particles that affects the material properties, while $\mathrm{HNO}_{3}$ treatment oxidizes the surface of the particles affecting the surface properties of the coke 38. As mentioned by Jaramillo et al [14, the size of the molecule of the oxidizing agent affects diffusive processes through the carbon particle; therefore, treatment with diluted oxygen can react within the particle in greater proportion relative to nitric acid. These results are important, since the PZC is a parameter that determines the pH selection during the impregnation of a catalyst. When the species to be impregnated is a cation, it would be useful to have a negatively charged support to increase the affinity between the support and the catalytic precursor, so the $\mathrm{pH}$ of the solution has to be greater than the PZC.

\begin{tabular}{|c|c|c|c|}
\hline Sample & PZC & IEP & PZC-IEP \\
\hline COKE & 6.6 & 4.3 & 2.3 \\
\hline CO36 & 4.0 & 3.6 & 0.4 \\
\hline $\mathrm{C} 12 \mathrm{M}$ & 4.4 & 3.5 & 0.9 \\
\hline
\end{tabular}

Figure 5 shows the TGA/DTGA analysis in inert atmosphere of the prepared the nitric acid treatments produce mainly groups which decompose between 450 

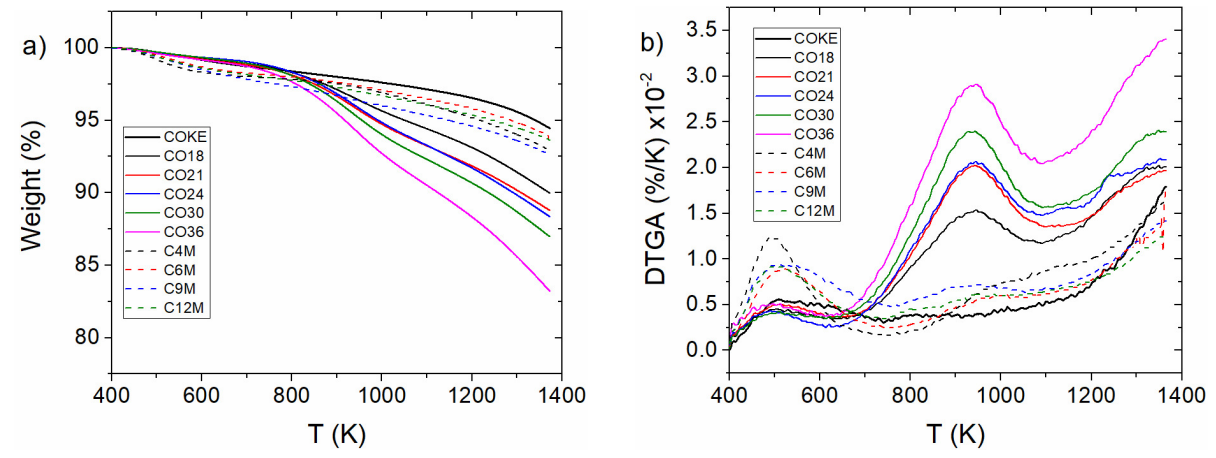

Figure 5: a) Thermogravimetric analysis and b) DTGA

and $600 \mathrm{~K}$ [17] and to a lesser extent oxygenated groups that decompose between 800 and $1100 \mathrm{~K}$; however, the amount of desorbed groups is not directly related to the acid concentration. The treatment in liquid phase could induce certain superficial groups that with the increase of temperature decompose more easily; while the gas phase treatment could lead to the formation of more stable surface groups and is more evident for more severe treatments.

The surface oxygen complexes formed during the preparation or subsequent functionalization of the coke are decomposed by heating, like all carbonaceous material, releasing $\mathrm{CO}$ and $\mathrm{CO}_{2}$ at different temperatures. To confirm these findings, thermal decomposition tests (TPD-MS) and DRIFTS spectra were carried out [39, 40, 41, 42, 43]. The $\mathrm{CO}_{2}$ desorption spectrum shows two peaks at 573-673 K and 873-1073 K and the CO desorption other two peaks at 973$1073 \mathrm{~K}$ and $1073-1173 \mathrm{~K}$ that are attributed to different surface structures with variable stability. The $\mathrm{CO}_{2}$ peaks result from the decomposition of the carboxylic acid groups at low temperature or lactones at higher temperatures; carboxylic anhydrides generate both $\mathrm{CO}$ and $\mathrm{CO}_{2}$ peaks at around $820 \mathrm{~K}$; and finally, phenols, ethers, carbonyls and quinones cause peaks in $\mathrm{CO}$ desorption [17. The total amount of each species in $\mu \mathrm{mol}$ were calculated from the integration of the peaks resulting from the decomposition of the signals of the corresponding $\mathrm{CO}$ and $\mathrm{CO}_{2}$ desorption spectra in Gaussian. The assignment of functional groups was performed according to the work of Figueiredo et al [17. 
From these results, the $\mu \mathrm{mol}$ of each oxygen-containing functional group in each found in the TGA/DTGA analysis of figure 5 , therefore, it can be said that the stability in the thermogravimetric test of the modified materials depends on the surface chemistry.

The DRIFTS spectra of the materials are presented in the figure 6, where bands with a certain level of development appear when they undergo oxidative treatments, with a greater emphasis on gas phase treatment. The most notorious spectral feature, for all solids, is the signal around $1620 \mathrm{~cm}^{-1}$; this signal is one of the most difficult to evaluate due to the different assignments made in the 350 literature [40]; for example, in the work of Figuereido et al. [17] for oxidized carbons in air, this band was assigned to groups $\mathrm{C}=\mathrm{O}$ associated to ketones and quinones, assignment that other researchers also present [43, 44, 45, 46, 47, 48]; likewise it may be due to the stretching of the aromatic $\mathrm{C}=\mathrm{C}$ bond $43,44,48,49$, [50, 51. The spectra of Figure 6 a corresponding to the solid treated with dilute 
Table 4: Amounts of $\mathrm{CO}$ and $\mathrm{CO}_{2}$ released in the TPD tests.

\begin{tabular}{cccccc}
\hline Sample & $\begin{array}{c}\text { Carb. } \text { acid }^{1} \\
\mathrm{CO}_{2} \mu \mathrm{mol} / \mathrm{g}\end{array}$ & $\begin{array}{c}\text { Lactone } \\
\mathrm{CO}_{2}+\mathrm{CO} \mu \mathrm{mol} / \mathrm{g}\end{array}$ & $\begin{array}{c}\text { Anhydride } \\
\mathrm{CO} \mu \mathrm{mol} / \mathrm{g}\end{array}$ \\
\hline $\mathrm{COKE}$ & 130.5 & 113.0 & 0.0 & 110.7 & 0.0 \\
$\mathrm{C} 4 \mathrm{M}$ & 177.1 & 135.4 & 0.0 & 79.0 & 44.0 \\
$\mathrm{C} 6 \mathrm{M}$ & 224.0 & 19.0 & 211.3 & 6.3 & 27.9 \\
$\mathrm{C} 9 \mathrm{M}$ & 243.2 & 20.3 & 209.7 & 4.0 & 39.4 \\
$\mathrm{C} 12 \mathrm{M}$ & 192.2 & 36.1 & 158.4 & 4.0 & 40.0 \\
$\mathrm{CO} 18$ & 271.8 & 165.7 & 0.0 & 35.8 & 87.2 \\
$\mathrm{CO} 21$ & 326.9 & 167.4 & 0.0 & 36.4 & 86.6 \\
$\mathrm{CO} 24$ & 341.3 & 202.6 & 0.0 & 29.4 & 93.6 \\
$\mathrm{CO} 30$ & 462.2 & 181.7 & 0.0 & 29.5 & 93.4 \\
$\mathrm{CO} 36$ & 501.2 & 177.4 & 0.0 & 31.6 & 91.4 \\
\hline
\end{tabular}

355

oxygen highlights the evolution of the band around $1732 \mathrm{~cm}^{-1}$ associated with groups carboxylic acid, anhydride and lactone [17, 43, 44, 48, 50, 51, 52, 53, 54]. Likewise, it was observed the band to $1620 \mathrm{~cm}^{-1}$ related groups with lower acidity. The DRIFT spectra of the CXM series of figure 6p suggests that the modification with nitric acid does not alter the infrared spectrum except in the case of treatment with the highest concentration of nitric acid that produced a band of higher frequency around $1728 \mathrm{~cm}^{-1}$ associated with carboxylic acid, anhydride and lactone groups [17, 43, 44, 46, 48, 50, 51, 52, 53]. The difference spectra between those of the treated solids (CO36, CO21 and CO18) and the untreated one $(\mathrm{COKE})$ is shown in the inlet of figure 6a. There, it is clearly observed that, after the oxidation treatment, the band at higher frequencies appears and both are intensified with the oxidation time. Significantly, these results are consistent with increased acidity and groups assigned to signals CO and $\mathrm{CO}_{2}$ in the TPD analysis.

To observe the changes caused by the oxidative treatments, the spectrum of the COKE and the spectra difference of the most oxidized materials are shown in 

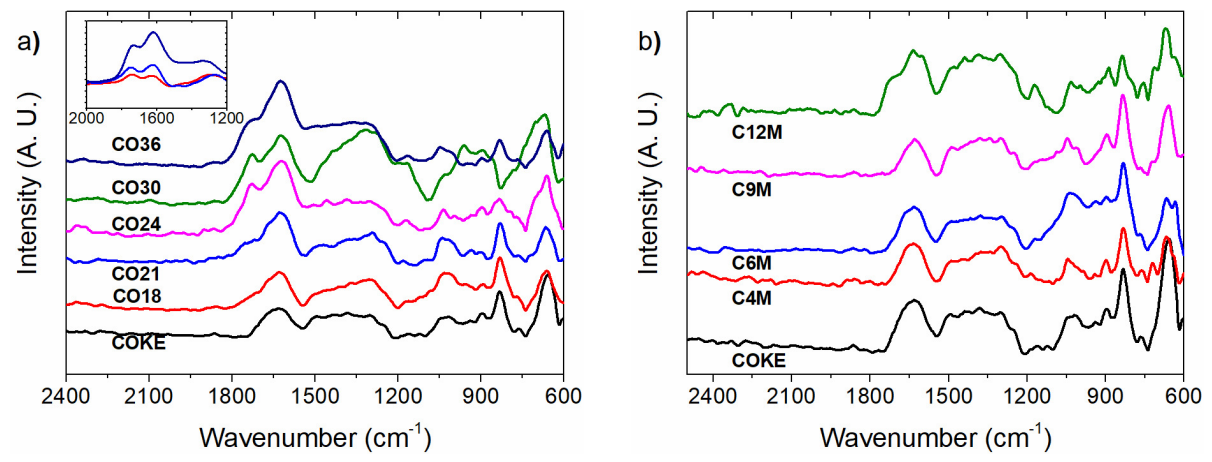

Figure 6: DRIFT spectra a) CO series b) CXM series

figure 7 Positive bands around 3050, 830 and $660 \mathrm{~cm}^{-1}$ assigned to aromatic C$\mathrm{H}$ are observed in the COKE [55]. The low band intensity at $3050 \mathrm{~cm}^{-1}$ is due to the high degree of aromatic condensation [55. Also, at $1620 \mathrm{~cm}^{-1}$ can be seen, which as mentioned above, the band $\mathrm{C}=\mathrm{O}$ associated with ketone and quinone groups. The band at $1027 \mathrm{~cm}^{-1}$ is related to the tension of the $\mathrm{C}-\mathrm{O}$ bond, which in combination with the one that appears at $1320 \mathrm{~cm}^{-1}$ can be associated with $\mathrm{C}-\mathrm{O}-\mathrm{C}$ in ethers [56]. Due to bands around $3500 \mathrm{~cm}^{-1}$ corresponding to $\mathrm{OH}$ are not observed, it indicates that there are no phenols or water adsorbed in the COKE, confirming the behavior of the material in the TGA/DTGA around $373 \mathrm{~K}$ and in the DTP-MS tests in which there is no evidence of the existence of phenols. The spectra difference between the most oxidized materials (CO36 and $\mathrm{C} 12 \mathrm{M}$ ) and the COKE of figure 7 indicate few changes with respect to cokes treated in nitric acid, only a slight drop of the aromatic bands and the $\mathrm{C}-\mathrm{O}$ band of the COKE and the band at $1740 \mathrm{~cm}^{-1}(\mathrm{C}=\mathrm{O}$, carbonyls). The treatments in air incorporate more oxygen to the surface, observing a decrease in the bands of the aromatics, as well as the evolution of the bands at 1620, 1740 and $1320 \mathrm{~cm}^{-1}$. It is important to highlight the appearance of the band at $3500 \mathrm{~cm}^{-1}$ (O-H bound) due to the formation of phenol groups as observed in the TPD-MS.

Thus, it was found that selected oxidative treatments modify the surface chemistry of the coke, incorporating oxygenated groups of different nature and in 


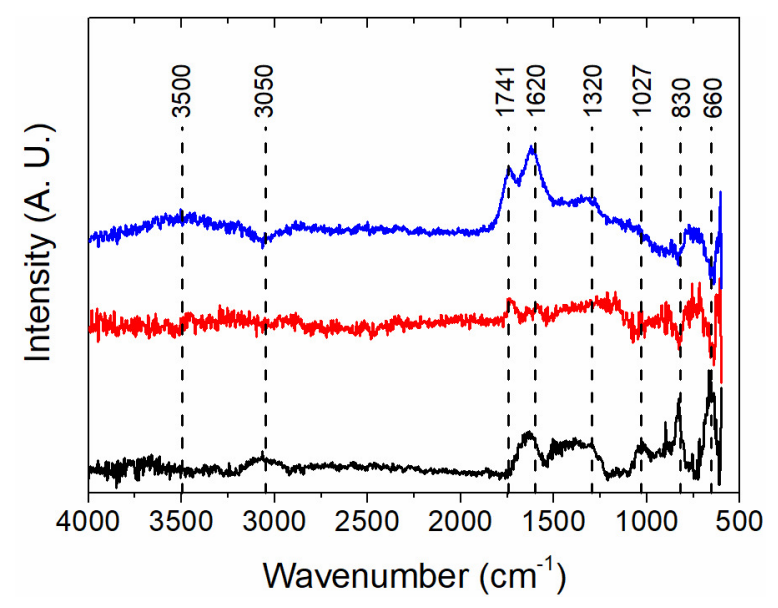

Figure 7: DRIFT spectra COKE and spectra difference of $\mathrm{C} 12 \mathrm{M}$ and $\mathrm{CO} 36$

different proportions. Treatment with diluted oxygen promotes the formation of more acidic groups, such lactones and, in smaller proportion, carbonyl-quinone and carboxylic acid; while the incorporation of oxygenated groups by the $\mathrm{HNO}_{3}$ treatment is dependent on the concentration used; at low concentrations the formation of lactone and carbonyl-quinone groups are increased and, at high concentrations, anhydride and carboxylic acid type groups are increased. These results are consistent with the discussed TPD and TGA/DTGA results. The incorporation of these oxygenated groups to the surface of the coke provides the anchor sites for the active species of the catalyst. Thus, in this work, the materials with greater and / or lesser presence of these groups are selected for the synthesis of the iron catalysts supported on the carbonaceous material. The catalysts prepared on COKE, CO18, CO36, C4M and C12M were characterized by XRF, DRX, RAMAN, Dynamic oxygen chemisorption, and SEM-EDX.

Table 5 presents the mass percentage of iron and sulfur in the prepared catalysts, determined by XRF, which are corrected against the percentage found in the COKE; thus, the amount of iron and sulfur correspond to the amount incorporated during the impregnation stage. The support modified with nitric acid presents better efficiency in the impregnation; however, it should be noted that since the $\mathrm{S} / \mathrm{Fe}$ molar ratio is not close to $2\left(\mathrm{FeS}_{2}\right)$, the crystalline iron 
Table 5: Iron, sulfur content and sulfur/iron molar ratio of the catalysts.

\begin{tabular}{cccc}
\hline & $\mathbf{F e} \boldsymbol{\%}(\mathbf{w} / \mathbf{w})$ & $\mathbf{S ~} \%(\mathbf{w} / \mathbf{w})$ & $\mathbf{S} / \mathbf{F e}$ \\
\hline $\mathrm{COKE}-\mathrm{Fe}$ & 17.2 & 3.7 & 0.4 \\
$\mathrm{C} 4 \mathrm{M}-\mathrm{Fe}$ & 23.2 & 8.4 & 0.6 \\
$\mathrm{C} 12 \mathrm{M}-\mathrm{Fe}$ & 26.4 & 11.4 & 0.7 \\
$\mathrm{CO} 18-\mathrm{Fe}$ & 18.7 & 6.8 & 0.6 \\
$\mathrm{CO} 36-\mathrm{Fe}$ & 17.8 & 11.8 & 1.2 \\
\hline
\end{tabular}

sulphides formed correspond to sulfur-poor phases. This may be due to the loss of sulfur during the activation of the catalyst since it is carried out at a temperature higher than that of decomposition of the carboxylic acid groups of the support. On the other hand, it is observed that the gas phase functionalized supports present an iron amount similar to that of COKE-Fe but CO36-Fe has the highest $\mathrm{S} / \mathrm{Fe}$ molar ratio and the highest total amount of oxygenated groups indicating that the iron sulfide species formed are the enriched in sulfur such as Greigite $\left(\mathrm{Fe}_{3} \mathrm{~S}_{4}\right)$.

Figure 8 shows the Raman spectra of the COKE and C12M supports and their corresponding catalysts, displaying that the COKE-Fe presents the characteristic bands of pyrite $\mathrm{Ag}\left(374 \mathrm{~cm}^{-1}\right)$ and $\mathrm{Eg}\left(336 \mathrm{~cm}^{-1}\right)$ [57]. The Raman spectra have two dominant bands at $1350 \mathrm{~cm}^{-1}$ band D (disorder) and at 1599 $\mathrm{cm}^{-1}$ band $\mathrm{G}$ (graphitic) common to metallurgical cokes, the relative intensity of the G-band demonstrates a high microstructural order within the graphitic planes of the coke [58. In addition, it is evident that the impregnation does not significantly affect the spectral characteristics of the support.

The X-ray diffraction patterns are presented in figure 9 for the catalysts, the active phase and the COKE support without modification, where it is observed an acute and intense signal located at $26.6^{\circ} 2 \theta$ which corresponds to the 002 plane of graphitic microcrystals and (101) peak at $43^{\circ} 2 \theta$ [59], typical of carbonaceous materials, indicating the high degree of ordering of COKE as a consequence of the heat treatment in the absence of oxygen to which it was 


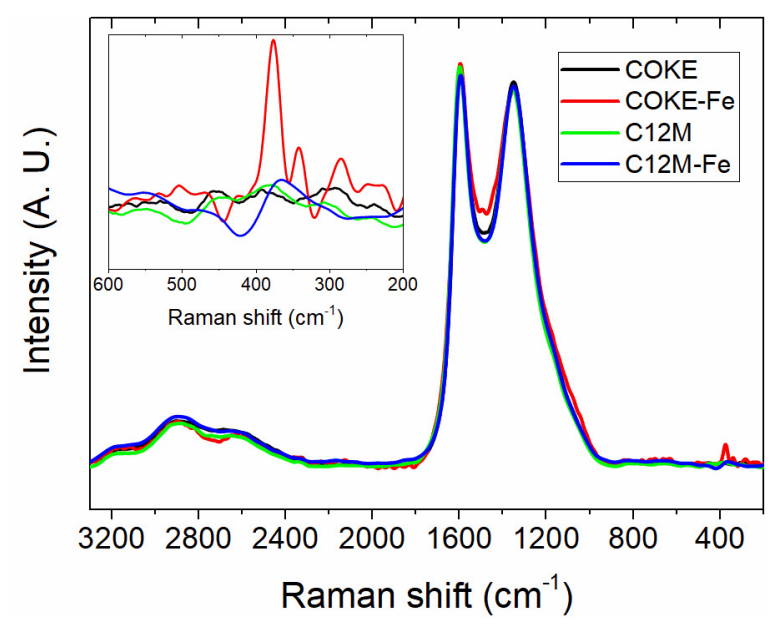

Figure 8: Raman spectra of the COKE and C12M supports and their corresponding Fe catalysts.

subjected during its manufacturing process. The dotted lines indicate the characteristic diffraction pattern of pyrite, which cannot be detected in the COKE due to its low proportion [60, although, peaks are observed in 37, 40, 44 and 50 $2 \theta$ associated with inorganic material where mainly aluminosilicates are highlighted. Additionally, it is observed that the catalysts present the characteristic reflections of pyrite 61] emphasizing that for the catalyst enriched in oxygenated groups, the intensity of these signals is greater. When calculating the average crystallite size for coke and pyrite, table 6 is obtained; where it is observed that the impregnation increases between 5.0 and 1.2 times, the size of the graphitic microcrystals of the catalysts against the unmodified support. The increase in this parameter can be interpreted as the increase in the interplanar distance of the graphitic layers due to the formation of pyrite between the aromatic layers of the coke. In this way, the functionalization with nitric acid slightly affects the size of the graphitic microcrystals while in the materials modified with diluted oxygen, the decrease in the size of the coke crystallite is favored for the CO36Fe catalyst. At low concentrations of nitric acid, the decrease in the crystallite size of the pyrite is observed, but the smallest size of pyrite is found in the catalyst with the longest exposure time in diluted oxygen. Thus, the produc- 


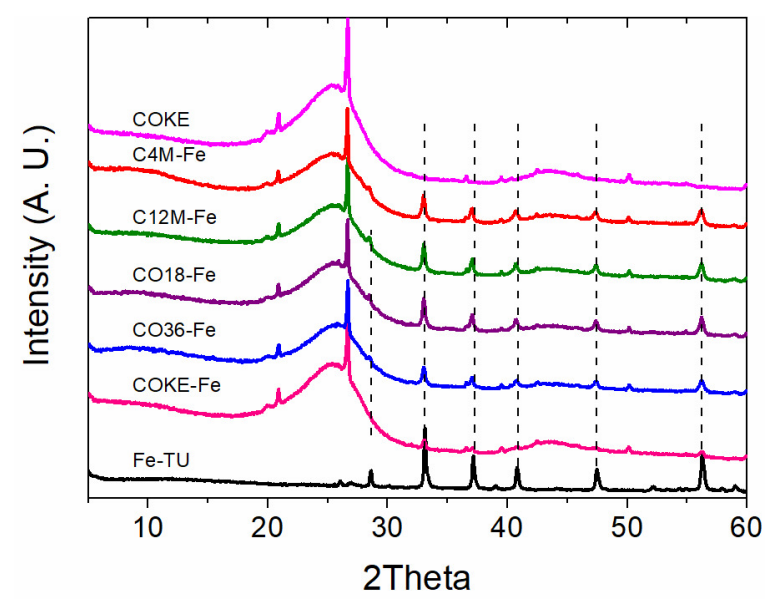

Figure 9: The X-ray diffraction patterns.

tion of smaller crystallites is favored reflecting an increase in dispersion possibly because it corresponds to the catalyst prepared with the support enriched in the most total amount of oxygen groups. In addition, this catalyst develops the largest surface area during its functionalization, generating enough space for the growth of the pyrite to advance towards the outside of the graphene layers of the coke. On the contrary, materials with low surface area, such as those of the CXM series, the growth of pyrite is conditioned inside the graphitic planes of the support. These results are consistent with the fact that the generation of active phases in the external part of the catalyst is especially important in reactions where the reagents are macromolecules that do not diffuse rapidly as in direct coal liquefaction [62] .

To determine the relative dispersion of the active phase, the dynamic chemisorption of oxygen on the catalysts is used and, by integrating the signals from the mass spectra, the total amount of oxygen that was chemisorbed was calculated, correcting it with respect to the chemisorbed by the support. These results are shown in the table 7 indicating that both treatment with oxygen and nitric acid improves the relative dispersion of the active phase. These results are consistent with the amount of $\mathrm{CO}$ and $\mathrm{CO}_{2}$ desorbed, explaining that the greater the number of superficial functional groups in the solid, the greater the dispersion. 
Table 6: Crystallite size for coke and pyrite in the catalysts.

\begin{tabular}{ccc} 
& \multicolumn{2}{c}{ Crystallite size (nm) } \\
& Coke & Pyrite \\
\hline COKE & 58.3 & - \\
COKE-Fe & 255.1 & 57.9 \\
C4M-Fe & 199.1 & 50.5 \\
C12M-Fe & 240.1 & 57.9 \\
CO18-Fe & 291.6 & 55.2 \\
CO36-Fe & 68.0 & 47.6 \\
\hline
\end{tabular}

Table 7: Oxygen chemisorption of catalysts.

\begin{tabular}{ccc}
\hline Catalyst & $\mu \mathrm{mol} \mathrm{O}_{2} / \mathrm{g}$ of catalyst & $\mu \mathrm{mol} \mathrm{O}_{2} / \% \mathrm{Fe}$ \\
\hline $\mathrm{COKE}-\mathrm{Fe}$ & 12.6 & 0.4 \\
$\mathrm{C} 4 \mathrm{M}-\mathrm{Fe}$ & 16.6 & 0.7 \\
$\mathrm{C} 12 \mathrm{M}-\mathrm{Fe}$ & 13.7 & 0.5 \\
$\mathrm{CO} 18-\mathrm{Fe}$ & 30.7 & 1.6 \\
$\mathrm{CO} 36-\mathrm{Fe}$ & 32.1 & 1.8 \\
\hline \multicolumn{3}{c}{$*$ taken from the XRF results }
\end{tabular}
the smaller crystallite size of the pyrite measured by XRD, which was favored in the material enriched with phenol and lactone groups.

To study the morphology of the catalysts and the COKE, the SEM micrographs were taken, as shown in figure 10, where a rough and cavernous surface 475 with low porosity can be observed. The magnification in the 3500X micrograph allows observing a texture in the form of curved flow channels commonly called anisotropic flow lines 63 produced by the plastic stage that the coal undergoes during the coking process where these lines are produced when the volatile compounds generated escape.

Figure 11 corresponds to a mapping in each of the analyzed areas in order to determine the distribution of iron and sulfur on the surface of the materials. A 

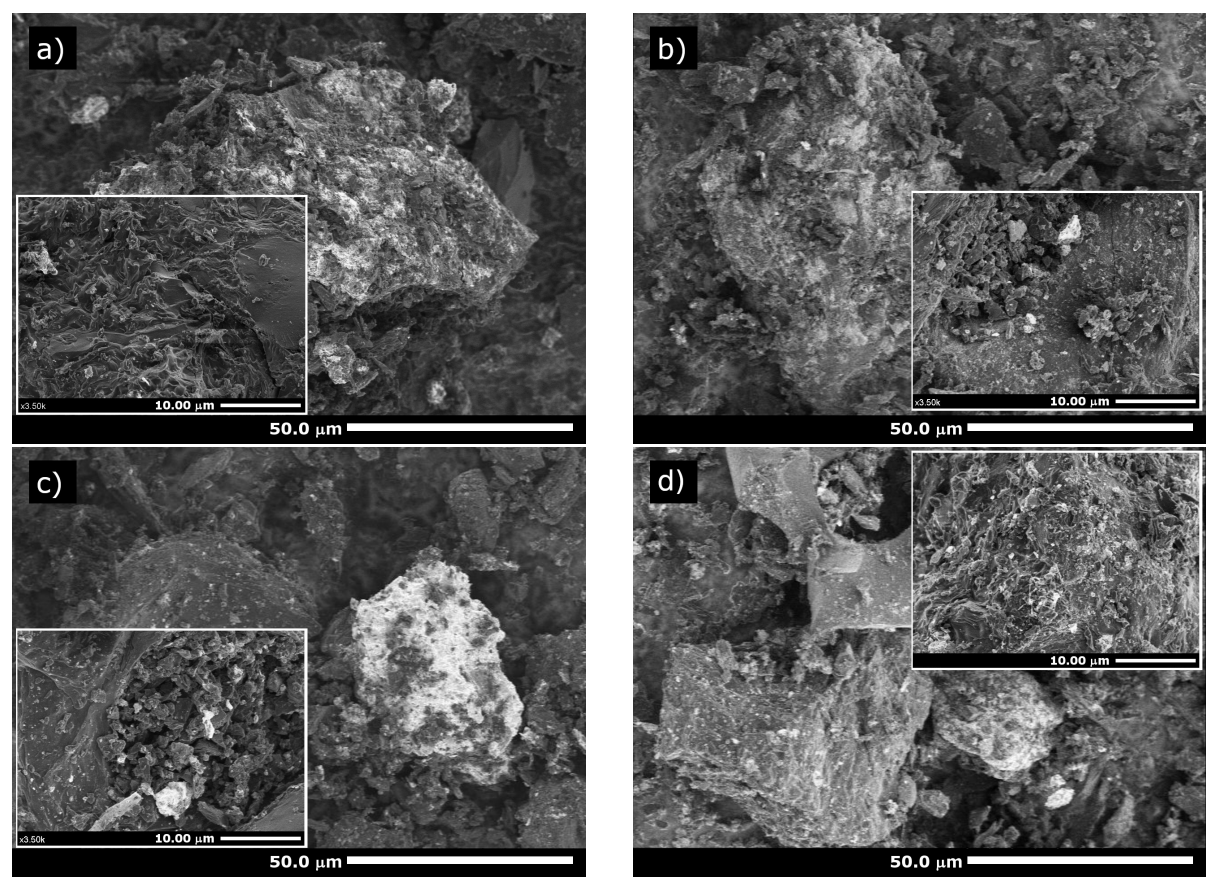

Figure 10: Scanning electron microscopy 1000X and 3500X for the catalysts and coke A.COKE, B.COKE-Fe, C.CO36-Fe and D.C12M-Fe 
high concentration of these elements was found. The areas of highest contrast (blank) predominant on the surface of the particles are possibly aluminosilicates, as observed in the XRD. Particles rich in iron and sulfur that grew on an edge of a coke grain are observed. The EDX analysis of the COKE and catalysts shown in figure 12 shows the contents of carbon, oxygen, aluminum and silicon as main components. The scanning in the analyzed points allows detecting the presence of iron and sulfur in a greater proportion with respect to the COKE. In general, the modification of coke produces an increase in iron and sulfur-rich particles; COKE-Fe shows a slight increase in yellow spots that correspond to sulfur species. These results show that the iron and sulfur in the catalysts are associated forming the iron sulphides confirming what was found by XRF and XRD.

From the stability test of the coke used as a support in the catalysts it was established that the coke does not react because no THF soluble component was extracted, and it was confirmed that the mass of the charged solid is the same, and the particle size does not change as determined by granulometric analysis, this is due to its mechanical resistance. Therefore, after the reaction was carried out, the coke was separated from the residues by sieving due to the difference in particle size (coke $1.33 \mathrm{~mm}$ and coal less than $125 \mu \mathrm{m}$ ).

The results of the DCL catalytic tests are shown in figure 13 , where it is observed that the reaction without catalyst (blank) reaches a conversion of $47 \%$, a yield to oils of $24 \%$ and to asphaltenes and preasphaltenes less than $2 \%$; this behavior is due to the fact that, during liquefaction, coal (RC) with a volatile matter content of $38 \%$ undergoes devolatilization and thermal cracking due to the rupture of its aromatic structure that preferentially leads to the production of gases and reactive fragments or free radicals that can be hydrogenated to a good extent without catalyst by the presence of the reactive atmosphere $\left(\mathrm{H}_{2}\right.$ and tetralin) if the temperature is high enough. These results contrast with those of the study developed by Jiménez et al. 25] who used a medium volatile bituminous Colombian coal (volatile matter content of $24 \%$ ) obtaining lower conversions and yields towards oils and a greater production of asphaltenes 


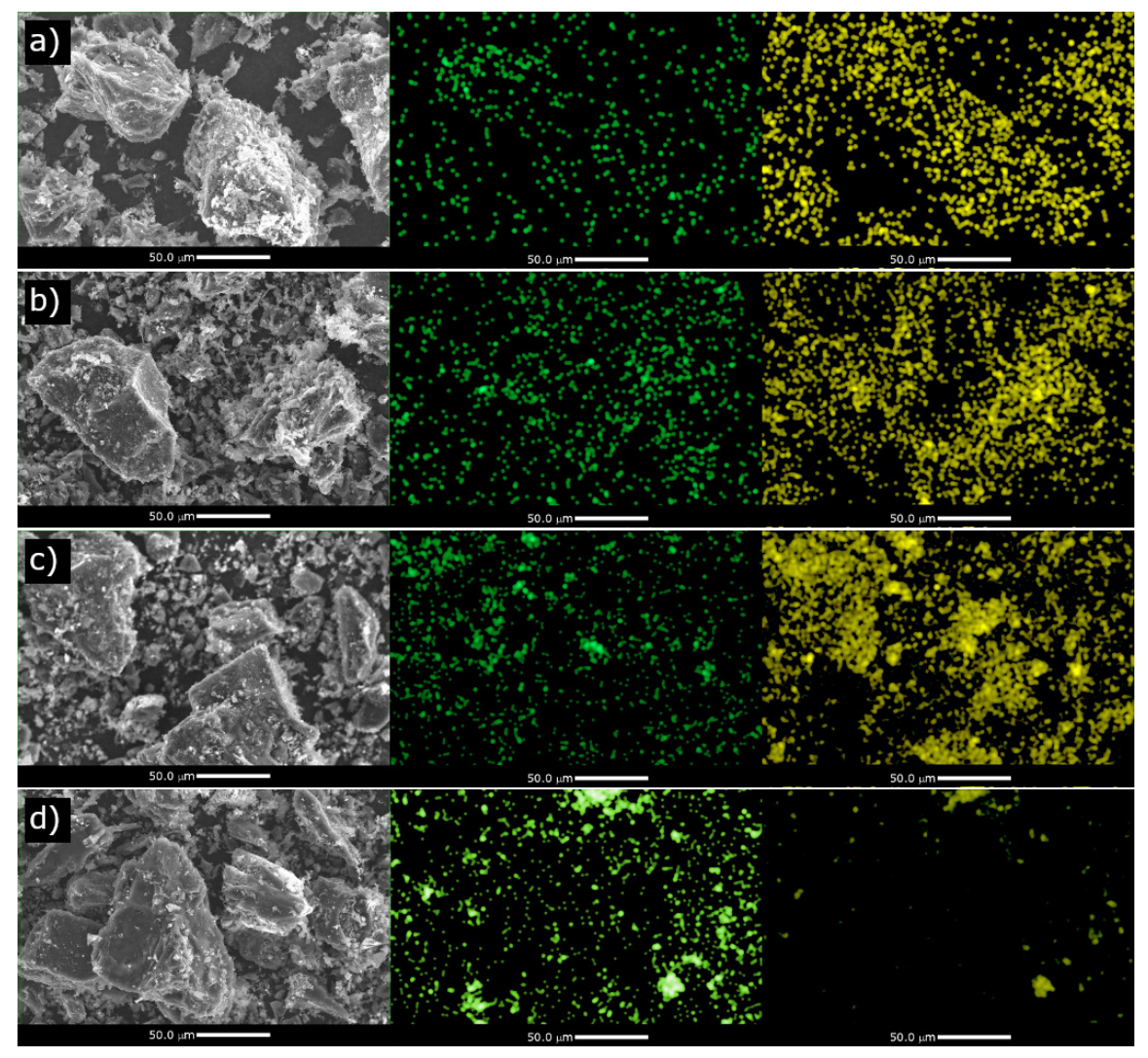

Figure 11: Scanning electron microscopy for catalysts and coke, A. COKE, B. COKE-Fe. C. CO36Fe and D. C12MFe. First column 500X, second and third column mapping for Fe and $\mathrm{S}$ respectively. 


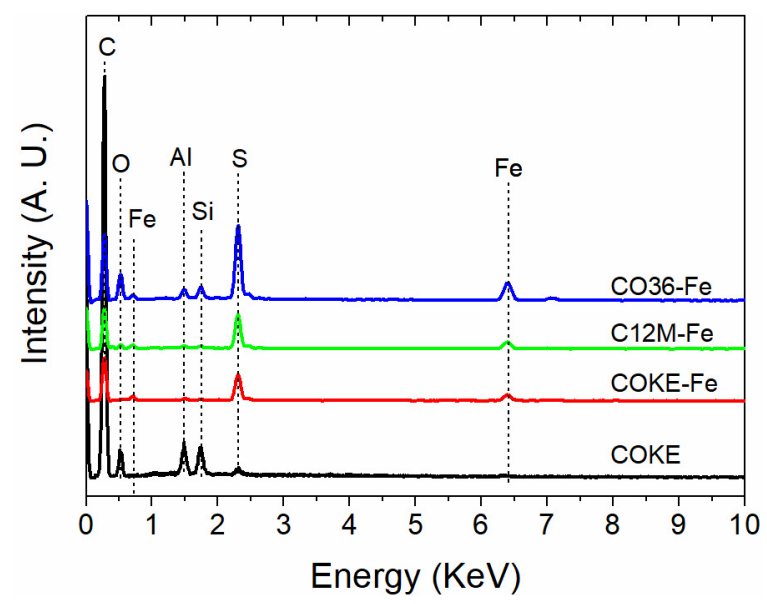

Figure 12: EDX analysis for COKE and catalysts.

and preasfaltenes that reach around 18 and $21 \%$ respectively, under the same reaction system, which is consequence of the type of coal in the process.

In the test using only the support (COKE), a conversion close to $60 \%$ is observed, yields towards oils around $39 \%$ and a slight decrease in the production of gases (18\%). When compared with the test without catalyst, it is evident that the increase of $13 \%$ in the conversion and $15 \%$ of the selectivity to oils is due to the catalytic effect of the mineral matter, composed mainly of aluminosilicates with traces of pyrite and oxides of iron, titanium and strontium and others present in the COKE derived from the starting coals.

For the COKE-Fe, it is evident that the deposited iron sulfide increases the conversion up to $72 \%$, showing higher production of gases and asphaltenes and a slight increase of oils. When analyzing the performance of the catalysts, whose 525 supports were modified, it is found that regardless of the concentration of the $\mathrm{HNO}_{3}$ and the oxidizing agent used, the conversion increases between 6 and $8 \%$ compared to the COKE-Fe. It should be noted that in the materials modified with diluted oxygen, the solid CO36-Fe with the smallest crystallite size of the pyrite, presents the maximum performance towards oils of all the catalysts studied. The existence of the catalysts favors the increase of the conversion up to $80 \%$ and the yields towards oils and gases in comparison with the tests without 


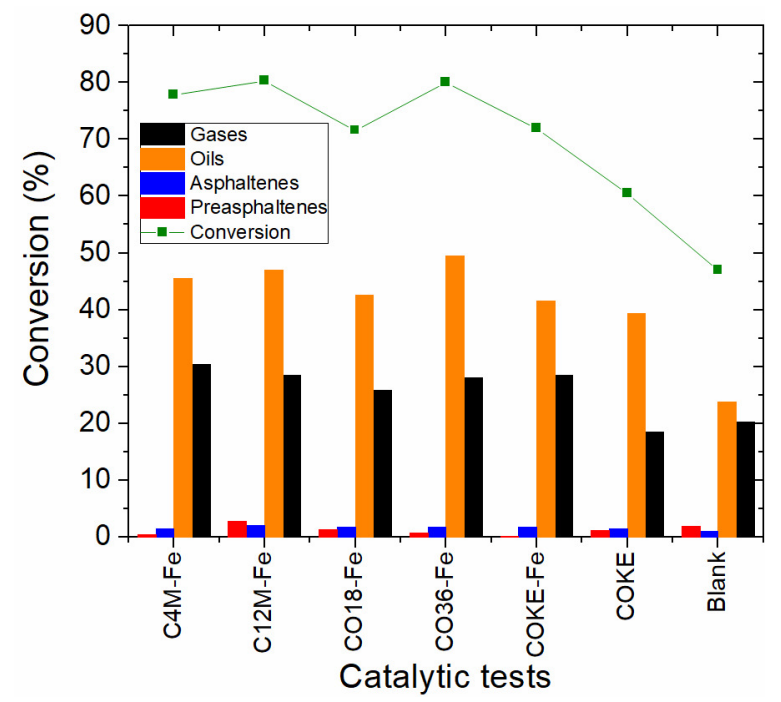

Figure 13: DCL catalytic test.

catalyst (blank) since the presence of the catalysts favors the hydrogenation reactions affecting the re-polymerization reactions which is important because it decreases the hydrogen required to stabilize the reactive fragments, remove sulfur and nitrogen and regenerate the solvent. These results show the capacity per se of the high volatile bituminous coal used to crack and hydrogenate, decreasing the heavier fractions in favor of the fractions of oils and gases.

The behavior of the C4M-Fe and C12M-Fe catalysts can possibly be attributed to the fact that the presence of the surface groups of carboxylic acid and anhydride type favor the location of the active phase which compensates for the fact that the relative dispersion in these catalysts are lower than the catalysts of the $\mathrm{CO}$ series whose relative dispersion is double that of the CXM series and whose surface chemistry is enriched in lactone and phenol groups. However, for the solid CO36-Fe its textural and surface chemistry characteristics, as well as, the formation iron sulfide species enriched in sulfur such as Greigite $\left(\mathrm{Fe}_{3} \mathrm{~S}_{4}\right)$ give it the ability to produce more oil yield. Additionally, these results confirm that the growth of the pyrite crystals towards the external part of the graphitic lamellas of the support allow a greater interaction of the coal (RC) 
macromolecules with the active site and therefore the conversion and selectivity towards the production of the lighter fractions [34]. In this way, the efficiency of the reaction defined as oil yield increases in all cases where the catalyst support was modified, because the oxygenated groups produced, regardless of their nature on the surface of the coke (table 4), increase the capacity of the support to capture species rich in iron and sulfur (table 5); which improves the dispersion measured in the oxygen chemisorption experiment (table 7) and the decrease in the size of the pyrite crystal measured by XRD (table 6).

Figure 14 shows the relation of $\mu \mathrm{mol} \mathrm{CO} / \mu \mathrm{mol} \mathrm{CO}_{2}$ as a function of the conversion in direct liquefaction of coal (DCL). In this figure it is observed that the supported catalysts of the CXM series improve the conversion even though the $\mathrm{CO} / \mathrm{CO}_{2}$ ratio does not change significantly with respect to the $\mathrm{COKE}$ Fe, showing that the quantity of the oxygenated groups is a more important parameter than the acidity in the performance of the catalyst since the $\mathrm{CO} / \mathrm{CO}_{2}$ ratio is inversely related to the acidity of the materials in which low ratios indicate the presence of more acidic groups and higher values suggest less acidic groups [17].

Supports modified with oxygen have different oxygenated groups to those of COKE-Fe, however, the conversion of the CO18-Fe catalyst is slightly lower, which indicates that regardless of the type of oxidant used and the nature of the incorporated groups, the highest oil yield can be achieved when the porosity of the material allows coal macromolecules access to the sites where the active phase has been anchored. These results show that the carbonaceous material has an affinity with the structure of the coal and that the large pores of the coke facilitate the diffusion of macromolecules derived from coal pyrolysis through the catalyst, a factor that greatly favours the interaction of the active phase of the catalyst with the formed radicals, reducing polymerization, condensation reactions and increasing the performance of liquid products. The functionalization of the metallurgical coke allowed a good interaction with the active phase improving its dispersion and conversion of DCL.

Finally, it is observed that oxygenated groups incorporated in the catalytic 


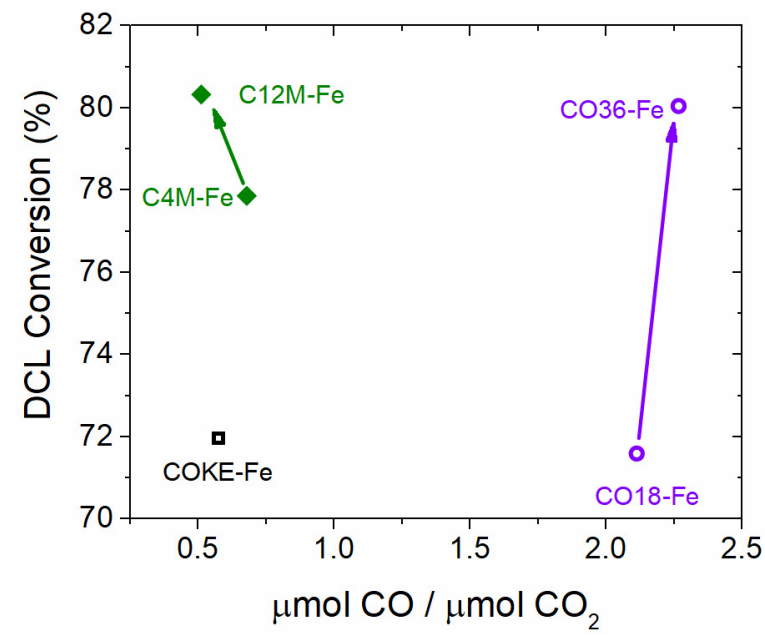

Figure 14: Conversion of the DCL versus $\mathrm{CO} / \mathrm{CO}_{2}$ ratio.

580 CO36-Fe catalyst, which has a greater surface area and relative dispersion.

\section{Conclusions}

The mineral matter present in small amount in the support used shows

585 a catalytic effect increasing the conversion compared to the reaction without catalyst. The proposed modification of the support through treatments with nitric acid and diluted oxygen increase the conversion of coal and the production of oils by the presence of surface oxygenated groups where the catalyst with the highest quantity of oxygenated groups anchored in the support allows the precursor-support interaction improving the dispersion of the active phase. This fact is of special importance in the transformation of high volatile bituminous coal to obtain liquid fuels since it is the fraction of interest and greater added value.

The DCL, although it proceeds in a good quantity without catalyst is a 595 very complex process since it involves the contact of solid, liquid and gaseous phases in such a way that, a small improvement in the conversion and the yield 
towards oils by action of the supported catalyst in functionalized coke it results in a lower consumption of hydrogen, lower production of gases and asphaltenes, more production of oils and in general, in lower costs of the process.

\section{Acknowledgment}

The authors are grateful to Universidad Nacional de Colombia for financial support through the scholarship "student assistant" and the Dirección de Investigación sede Bogotá (DIB) for financial support through the program support for postgraduate students.

\section{References}

\section{References}

[1] T. Kabe, A. Ishihara, E. W. Qian, I. P. Sutrisna, Y. Kabe, Methods of Classification and Characterization of Coal, in: Studies in Surface Science and Catalysis, 2004, pp. 1-79. doi:10.1016/S0167-2991(04)80006-5.

[2] X. Li, H. Hu, L. Jin, S. Hu, B. Wu, Approach for promoting liquid yield in direct liquefaction of Shenhua coal, Fuel Processing Technology 89 (11) (2008) 1090-1095. doi:10.1016/j.fuproc.2008.05.003.

[3] F. Derbyshire, T. Hager, Coal liquefaction and catalysis, Fuel 73 (7) (1994) 1087-1092. doi:10.1016/0016-2361(94)90242-9.

[4] U. Priyanto, K. Sakanishi, O. Okuma, I. Mochida, Catalytic Activity of FeMoNi Ternary Sulfide Supported on a Nanoparticulate Carbon in the Liquefaction of Indonesian Coals, Industrial \& Engineering Chemistry Research 40 (3) (2001) 774-780. doi:10.1021/ie000432i.

[5] J. Stihle, D. Uzio, C. Lorentz, N. Charon, J. Ponthus, C. Geantet, Detailed characterization of coal-derived liquids from direct coal liquefaction on supported catalysts, Fuel 95 (2012) 79-87. doi:10.1016/j.fuel.2011. 11.072 
[6] G. P. Huffman, B. Ganguly, J. Zhao, K. R. Rao, N. Shah, Z. Feng, F. E. Huggins, M. M. Taghiei, F. Lu, I. Wender, V. R. Pradhan, J. W. Tierney, M. S. Seehra, M. M. Ibrahim, J. Shabtai, E. M. Eyring, Structure and Dispersion of Iron-Based Catalysts for Direct Coal Liquefaction, Energy and Fuels 7 (2) (1993) 285-296. doi:10.1021/ef00038a020.

[7] V. R. Pradhan, J. W. Tierney, I. Wender, G. P. Huffman, Catalysis in direct coal liquefaction by sulfated metal oxides, Energy \& Fuels 5 (3) (1991) 497-507. doi:10.1021/ef00027a024

[8] F. Rodríguez-Reinoso, A. Sepúlveda-Escribano, Porous carbons in adsorption and catalysis, in: Handbook of Surfaces and Interfaces of Materials, Vol. 5, Elsevier, 2001, pp. 309-355. doi:10.1016/B978-012513910-6/ 50066-9.

[9] L. R. Radovic, Physicochemical Properties of Carbon Materials: A Brief Overview, in: Carbon Materials for Catalysis, John Wiley \& Sons, Inc., Hoboken, 2008, pp. 1-44. doi:10.1002/9780470403709.ch1.

[10] F. Rodríguez-Reinoso, The role of carbon materials in heterogeneous catalysis, Carbon 36 (3) (1998) 159-175. doi:10.1016/S0008-6223(97) 00173-5

[11] N. O. Briceño, Y. Guzmán, J. D. J. Díaz, Grupos superficiales en materiales carbonosos. Caracterización por diferentes técnicas, Revista Colombiana de Química 36 (1) (2007) 121-130.

[12] A. Bhatnagar, W. Hogland, M. Marques, M. Sillanpää, An overview of 645 the modification methods of activated carbon for its water treatment

【 applications, Chemical Engineering Journal 219 (2013) 499-511. doi: 10.1016/J.CEJ.2012.12.038

[13] C. Moreno-Castilla, M. A. Ferro-Garcia, J. P. Joly, I. Bautista-Toledo, F. Carrasco-Marin, J. Rivera-Utrilla, Activated Carbon Surface Modifications by Nitric Acid, Hydrogen Peroxide, and Ammonium Peroxydisul- 
fate Treatments, Langmuir 11 (11) (1995) 4386-4392. doi:10.1021/ $1 \mathrm{a} 00011 \mathrm{a} 035$

[14] J. Jaramillo, P. M. Álvarez, V. Gómez-Serrano, Oxidation of activated carbon by dry and wet methods, Fuel Processing Technology 91 (11) (2010) 1768-1775. doi:10.1016/j.fuproc.2010.07.018

[15] J. d. J. Díaz, L. M. Suárez, J. L. Figueiredo, Oxidative dehydrogenation of isobutane over activated carbon catalysts, Applied Catalysis A: General 311 (1-2) (2006) 51-57. doi:10.1016/j .apcata.2006.06.001.

[16] Q. Zhuang, T. Kyotani, A. Tomita, Dynamics of Surface Oxygen Complexes during Carbon Gasification with Oxygen, Energy \& Fuels 9 (4) (1995) 630634. doi:10.1021/ef00052a009.

[17] J. Figueiredo, M. Pereira, M. Freitas, J. Órfão, Modification of the surface chemistry of activated carbons, Carbon 37 (9) (1999) 1379-1389. doi: 10.1016/S0008-6223(98)00333-9.

[18] J. d. J. Díaz, Y. Y. Agámez, L. I. Rodríguez, O. Hernández, O. A. Villalba, J. A. Jiménez, Process for making a catalyst suitable for direct coal liquefaction and the catalyst thereof, US Patent 8.476,182 B2 (July 2, 2013).

[19] X. Mao, J. Li, P. Zhao, F. Hu, J. Zhong, W. Li, X. Zhu, X. Gu, Y. Wu, P. Huang, L. Chen, B. Ma, Q. Chang, Z. Shi, Nano-dispersed type catalyst for direct hydro-liquefaction of coal and preparation method of nanodispersed catalyst, Patent Application CN109126796 (A) (January 4, 2019).

[20] S. Li, Q. Deng, K. Wang, Iron-based catalyst, and preparation method therefor and use thereof, Patent Application WO/2016/176947 (A1) (November 16, 2016).

[21] D. Zou, X. Yang, H. Shui, X. Wang, C. Pan, Z. Wang, Z. Lei, S. Ren, S. Kang, Z. Li, J. Yan, C. Xu, Liquefaction of thermal extracts from cothermal dissolution of a sub-bituminous coal with lignin and reusability of 
Ni-Mo-S/Al2O3 catalyst, Journal of Fuel Chemistry and Technology 47 (1) (2019) 23-29. doi:10.1016/S1872-5813(19)30004-0.

[22] H. Shui, L. Yang, T. Shui, C. Pan, H. Li, Z. Wang, Z. Lei, S. Ren, S. Kang, Hydro-liquefaction of thermal dissolution soluble fraction of Shenfu subbituminous coal and reusability of catalyst on the hydro-liquefaction, Fuel 115 (2014) 227-231. doi:10.1016/j.fuel.2013.07.002

[23] H. Shui, H. Xu, Y. Zhou, T. Shui, C. Pan, Z. Wang, Z. Lei, S. Ren, S. Kang, C. C. Xu, Study on hydro-liquefaction kinetics of thermal dissolution soluble fraction from Shenfu sub-bituminous coal, Fuel 200 (2017) 576-582. doi:10.1016/j.fuel.2017.03.048

[24] Z. Wang, H. Shui, X. Gu, J. Gao, Study on the direct liquefaction reactivity of Shenhua coal catalyzed by $\mathrm{SO}_{4}^{2-} / \mathrm{ZrO}_{2}$ solid acid, Journal of Fuel Chemistry and Technology 38 (3) (2010) 257-263. doi:10.1016/ s1872-5813(10)60031-x

[25] J. Jiménez, O. Villalba, L. Rodríguez, O. Hernández, Y. Agámez, J. Díaz, $\mathrm{Co}, \mathrm{Fe}$ and $\mathrm{Ni}$ catalysts supported on coke for direct coal liquefaction, Revista Colombiana de Química 37 (2) (2008) 233-242.

[26] T. Kaneko, K. Tazawa, N. Okuyama, M. Tamura, K. Shimasaki, Effect of highly dispersed iron catalyst on direct liquefaction of coal, Fuel 79 (3-4) (2000) 263-271. doi:10.1016/S0016-2361(99)00160-X.

[27] A. Khelifi, M. Almazán-Almazán, M. Pérez-Mendoza, M. Domingo-García, F. López-Domingo, L. Temdrara, F. López-Garzón, A. Addoun, Influence of nitric acid concentration on the characteristics of active carbons obtained from a mineral coal, Fuel Processing Technology 91 (10) (2010) 1338-1344. doi:10.1016/j.fuproc.2010.05.004

[28] A. Rosenheim, V. J. Meyer, Über die Thiokarbamidverbindungen zweiwertiger Metallsalze, Zeitschrift für anorganische Chemie 49 (1) (1906) 13-27. doi:10.1002/zaac.19060490103. 
[29] J. S. Noh, J. A. Schwarz, Estimation of the point of zero charge of simple oxides by mass titration, Journal of Colloid and Interface Science 130 (1) (1989) 157-164. doi:10.1016/0021-9797(89)90086-6.

[30] X. Li, H. Hu, S. Zhu, S. Hu, B. Wu, M. Meng, Kinetics of coal liquefaction during heating-up and isothermal stages, Fuel 87 (4-5) (2008) 508-513. doi:10.1016/j.fuel.2007.03.041

[31] U. Priyanto, K. Sakanishi, O. Okuma, I. Mochida, Liquefaction of Tanito Harum coal with bottom recycle using FeNi and FeMoNi catalysts supported on carbon nanoparticles, Fuel Processing Technology 79 (1) (2002) 51-62. doi:10.1016/S0378-3820(02)00101-7.

[32] H. Hu, J. Bai, H. Zhu, Y. Wang, S. Guo, G. Chen, Catalytic Liquefaction of Coal with Highly Dispersed $\mathrm{Fe}_{2} \mathrm{~S}_{3}$ Impregnated in-Situ, Energy \& Fuels 15 (4) (2001) 830-834. doi:10.1021/ef000227f

[33] D. Ramos, L. Rodríguez, M. Barrera, Y. Agámez, J. Díaz, Direct catalytic liquefaction of coals. Effect of the temperature, Revista Colombiana de Química 39 (1) (2010) 131-139.

[34] T. Kaneko, S. Sugita, M. Tamura, K. Shimasaki, E. Makino, L. H. Silalahi, Highly active limonite catalysts for direct coal liquefaction, Fuel 81 (11-12) (2002) 1541-1549. doi:10.1016/S0016-2361(02)00079-0

[35] M. Thommes, K. Kaneko, A. V. Neimark, J. P. Olivier, F. RodriguezReinoso, J. Rouquerol, K. S. Sing, Physisorption of gases, with special reference to the evaluation of surface area and pore size distribution (IUPAC Technical Report), Pure and Applied Chemistry 87 (9-10) (2015) 10511069. doi:10.1515/pac-2014-1117.

[36] P. V. Samant, F. Gonçalves, M. M. A. Freitas, M. F. R. Pereira, J. L. Figueiredo, Surface activation of a polymer based carbon, Carbon 42 (7) (2004) 1315-1319. doi:10.1016/j.carbon.2004.01.034 
[37] P. Vinke, M. van der Eijk, M. Verbree, A. Voskamp, H. van Bekkum, Modification of the surfaces of a gasactivated carbon and a chemically activated carbon with nitric acid, hypochlorite, and ammonia, Carbon 32 (4) (1994) 675-686. doi:10.1016/0008-6223(94)90089-2.

[38] J. Menéndez, M. Illán-Gómez, C. y León, L. Radovic, On the difference between the isoelectric point and the point of zero charge of carbons, Carbon 33 (11) (1995) 1655-1657. doi:10.1016/0008-6223(95)96817-R.

[39] S. Haydar, C. Moreno-Castilla, M. Ferro-García, F. Carrasco-Marín, J. Rivera-Utrilla, A. Perrard, J. Joly, Regularities in the temperatureprogrammed desorption spectra of $\mathrm{CO} 2$ and $\mathrm{CO}$ from activated carbons, Carbon 38 (9) (2000) 1297-1308. doi:10.1016/S0008-6223(99)00256-0

[40] A. Dandekar, R. Baker, M. Vannice, Characterization of activated carbon, graphitized carbon fibers and synthetic diamond powder using TPD and DRIFTS, Carbon 36 (12) (1998) 1821-1831. doi:10.1016/ S0008-6223(98) 00154-7.

[41] C. A. Leon y Leon, L. R. Radovic, Interfacial chemistry and electrochemistry of carbon surfaces, Chemistry and Physics of Carbon, Taylor \& Francis, 1993.

[42] H. Boehm, Surface oxides on carbon and their analysis: a critical assessment, Carbon 40 (2) (2002) 145-149. doi:10.1016/S0008-6223(01) 00165-8

[43] P. E. Fanning, M. Vannice, A DRIFTS study of the formation of surface 755 groups on carbon by oxidation, Carbon 31 (5) (1993) 721-730. doi:10. 1016/0008-6223(93)90009-Y

[44] V. Gómez-Serrano, M. Acedo-Ramos, A. López-Peinado, C. ValenzuelaCalahorro, Oxidation of activated carbon by hydrogen peroxide. Study of 【 surface functional groups by FT-i.r., Fuel 73 (3) (1994) 387-395. doi: 10.1016/0016-2361(94)90092-2. 
[45] C. Moreno-Castilla, M. López-Ramón, F. Carrasco-Marín, Changes in surface chemistry of activated carbons by wet oxidation, Carbon 38 (14) (2000) 1995-2001. doi:10.1016/S0008-6223(00)00048-8

[46] B. Buczek, S. Biniak, A. Świątkowski, Oxygen distribution within oxidised active carbon granules, Fuel 78 (12) (1999) 1443-1448. doi:10. 1016/S0016-2361(99)00063-0

[47] C. Ishizaki, I. Martí, Surface oxide structures on a commercial activated carbon, Carbon 19 (6) (1981) 409-412. doi:10.1016/0008-6223(81) 90023-3.

[48] A. Koch, A. Krzton, B. Azambre, O. Heintz, J. V. Weber, Oxidation studies of chars using in-situ FTIR spectroscopy, AKK, 1998.

[49] B. K. Pradhan, N. Sandle, Effect of different oxidizing agent treatments on the surface properties of activated carbons, Carbon 37 (8) (1999) 13231332. doi:10.1016/S0008-6223(98)00328-5

775 [50] H. Marsh, A. D. Foord, J. S. Mattson, J. M. Thomas, E. L. Evans, Surface oxygen complexes on carbons from atomic oxygen: An infrared (IRS), high-energy photoelectron spectroscopic (XPS), and thermal stability study, Journal of Colloid and Interface Science 49 (3) (1974) 368-382. doi:10.1016/0021-9797(74)90381-6.

[51] J. Zawadzki, Infrared Spectroscopy in Surface Chemistry of Carbons, in: Chemistry and Physics of Carbon, Vol. 21, 1989, pp. 147-386.

[52] J. Venter, M. Vannice, Applicability of "drifts" for the characterization of carbon-supported metal catalysts and carbon surfaces, Carbon 26 (6) (1988) 889-902. doi:10.1016/0008-6223(88)90112-1.

785 [53] S. Biniak, G. Szymański, J. Siedlewski, A. Świa̧tkowski, The characterization of activated carbons with oxygen and nitrogen surface groups, Carbon 35 (12) (1997) 1799-1810. doi:10.1016/S0008-6223(97)00096-1. 
[54] W. Geng, T. Nakajima, H. Takanashi, A. Ohki, Analysis of carboxyl group in coal and coal aromaticity by Fourier transform infrared (FT-IR) spectrometry, Fuel 88 (1) (2009) 139-144. doi:10.1016/j.fuel.2008.07.027

[55] H. Machnikowska, A. Krzton, J. Machnikowski, The characterization of coal macerals by diffuse reflectance infrared spectroscopy, Fuel 81 (2) (2002) 245-252. doi:10.1016/S0016-2361(01)00125-9.

[56] J. Andrés, M. Bona, Analysis of coal by diffuse reflectance near-infrared spectroscopy, Analytica Chimica Acta 535 (1-2) (2005) 123-132. doi: $10.1016 / \mathrm{j}$.aca.2004.12.007

[57] C. Pisapia, M. Chaussidon, C. Mustin, B. Humbert, O and S isotopic composition of dissolved and attached oxidation products of pyrite by Acidithiobacillus ferrooxidans: Comparison with abiotic oxidations,

800 - Geochimica et Cosmochimica Acta 71 (10) (2007) 2474-2490. doi:10. 1016/j.gca.2007.02.021.

[58] G. Rantitsch, A. Bhattacharyya, J. Schenk, N. Keno, International Journal of Coal Geology Assessing the quality of metallurgical coke by Raman spectroscopy, International Journal of Coal Geology 130 (2014) 1-7. doi:10.1016/j.coal.2014.05.005

[59] M.-S. Park, S.-E. Lee, M. I. Kim, Y.-S. Lee, $\mathrm{CO}_{2}$ adsorption characteristics of slit-pore shaped activated carbon prepared from cokes with high crystallinity, Carbon letters 16 (1) (2015) 45-50. doi:10.5714/CL.2015.16. 1.045

[60] R. Sakurovs, D. French, M. Grigore, Quantification of mineral matter in commercial cokes and their parent coals, International Journal of Coal Geology 72 (2) (2007) 81-88. doi:10.1016/j.coal.2006.12.009

[61] N. Kumar, N. Raman, A. Sundaresan, Temperature evolution of nickel sulphide phases from thiourea complex and their exchange bias effect, Journal 
of Solid State Chemistry 208 (2013) 103-108. doi:10.1016/j.jssc. 2013. 10.010

[62] X. Liu, J. G. Khinast, B. J. Glasser, A parametric investigation of impregnation and drying of supported catalysts, Chemical Engineering Science 63 (18) (2008) 4517-4530. doi:10.1016/j.ces.2008.06.013

${ }_{820}$ [63] J. Vleeskens, B. Kwiecinska, G. Hamburg, C. Roos, Identification of coal pyrolysis products by scanning electron microscopy, Fuel Processing Technology 24 (1990) 35-43. doi:10.1016/0378-3820(90)90040-Y. 